76, 312 (1954); J. Chem. Soc., 1954, 3052.

[4] R. B. Woodward et al., J. Am. Chem. Soc., 76, 4749 (1954); R. B. Woodward, Experientia Supplementum II (1955).

[5] E. C. Kornfeld et al., J. Am. Chem. Soc., 76. 5256 (1954); 78, 3087 (1956).

[6] R. B. Woodward et al., J. Am. Chem. Soc., 78. 2023 (1956).

[7] W. E. Bachmann, W. Cole and A. L. Wilds, J. Am. Chem. Soc., 61, 974 (1939); 62, 824 (1940).

[8] G. Anner and K. Miescher, Helv. Chim. Acta, 31, 2173 (1948); 32, 1957 (1949); 33, 1379 (1950).

[9] W. S. Johnson et al., J. Am. Chem. Soc., 74, 2832 (1952).

[10] H. M. E. Cardwell, J. W. Cornforth, S. R. Duff, H. Holtermann, R. Robinson, J. Chem. Soc., $1953,361$.

[11] R. B. Woodward et al., J. Am. Chem. Soc., 74 4223 (1952).

[12] L. H. Sarett et al., J. Am. Chem. Soc., 74, 4974 (1952).

[13] W. S. Johnson et al., J. Am. Chem. Soc., 78, 6278 (1956).

[14] R. U. Lemieux and G. Huber, J. Am. Chem. Soc., 75, 4118 (1953); 78, 4117 (1956).

[15] V. du Vigneaud et al,, J. Am. Chem. Soc,, 76, 3115 (1954).

[16] J. Baddiley et al., J. Chem. Soc., 1949, 582; S. M. H. Christie et al., ibid., 1954, 46.

[17] Y. Abe et al., Proc. Japan. Acad., 30, 116, 119 (1954); J. Am. Chem. Soc., 75, 2567 (1953); 77,
1416 (1955); 78, 1416, 1422 (1956).

[18] R. B. Woodward et al., and D. H. R. Barton et al., J. Am. Chem. Soc., 76, 2852 (1954); J. Chem. Soc., 1957, 1131.

[19] J. Controulis et al., J. Am. Chem. Soc., 71, 2463 (1949).

[20] J. C. Sheehan ot al., J. Am. Chem. Soc., 79, 1262 (1957).

[21] K. Garzon et al., J. Am. Chem. Soc., 78, 4396 (1956); Chem. and Eng. News, 34, 5138 (1956).

[थ2] R. B. Woodward et al., Nature, 165, 928 (1950); J. Am. Chem. Soc., 71, 758, 72, 1428, 5351 (1950); Experientia, 6, 238 (1950).

[23] R. Robinson et al., J. Chem. Soc., 1932, 789; C. Schöpt et al., Ann., 497, 22 (1932).

[24] J. Ewing et al., Nature, 169, 618 (1952).

[25] E. C. duFeu, F. J. McQuillin and R. Robinson, J. Chem. Soc., 1937, 53.

[26] D. H. R. Barton et al., J. Chem. Soc., 1955, 2056.

[27] P. Karrer, Helv. Chim. Acta, 33, 1172 (1950); H. H. Inhoffen et al., Ann., 569, 237 (1950); 573, 1 (1951).

[28] S. S. Nigam and B. C. L. Weedon, Chemistry \& Industry, 1955, 1555.

[29] L. Crombie and A. G. Jacklin, Chem. \& Industry, 1955, 1186.

[30] H. Lindlar, Helv. Chim. Acta, 35, 446 (1952).

[31] G. Wittig and U. Schöllkopf, Chem. Ber., 87, 1318 (1954).

[32] S. Trippett, Chemistry \& Industry, 1956, 80.

\title{
豪米波段波导管远距离傳輸 研究方面的新發展
}

\author{
黄武汉
}

(中国科学院电子学研究所筹备委員会)

利用毫米波波殿的波导管傅輸系統是中距离和远 距离發选訉号的最新类型。这种傳輸訊号的方法和以 前的类型完全不同, 它的特点是傳检容量非常巨大, 比微波接力中繼䋐路大許多倍, 而且初步研究結果指 出它是非常經济的[1]。

一方面，由于波导管的一些优良特性，如極寬的 通頻带，不受外界气候、天然的及人为的干扰影响， 極低的骍耗等，使人們預期到在毫米波波水采用它作 远距离傅鍫的現实性。另一方面, 当波长小于 3 重米

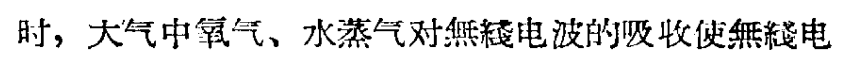
波在空中的远距离傅播受到妨碍。因此，对于比 3 监 米更短的没长，人們就需要用波导作远距离的傅輸 了。

为了实現远距离傳輸，必須利用圆波导，使信号 工作于 $\mathrm{TE}_{01}$ 波型上; 非利用毫米波使波导尺寸不致太 大，同时也可得到傳䢪極寬频带和極任寒耗等优点。

这种波导通訊綏的出現可以允許重新組織所有城 市間的电話通訊。实际上如果一根波导能谷的几十万 
路的电話, 那，大城市閏的波导通訊綫就可以将城 市閶的自䏡电話連接起来，因而在任何两大城市間只 須撥旿单的号碼就可以通話。不但如此, 波导通訊 的容量那么大，以致可以将城市間的軍用、民用和工 業系統的电䤄訊号利用这根波导綫联接起来。这种通 訊方法, 将使全国的各种通訊系統能够統一起来[?]。

在国防方面, 由于無綫电电子学新技术的进速發

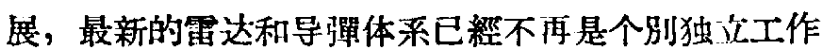
的設备了，而是把各种雷达、导彈設备、电子計算机、 远距离操絽、电悓設备等有机地联系起来的复杂系 梳。距离逢远的雷达站所获得的情报可以通过埋在地 下的波导傅狳圽速地傳送到指揮部。在軍事应用 上, 波导傳签比微波接力路优越, 因为前者不受 外界气候、天然的及敌人的干扰影响, 它的塞耗和噪 声电平也比微波接力䠌路低。事实上波导傳輸䋐的可 靠性将趋于 $100 \%$ ，这将是現代軍事傳龛訊息关踺所 在。

其次, 在科学技术方面, 利用 $\mathrm{TE}_{01}$ 波型的波导 傅稀的研究是無程电技术的最新展方向之一，它是 微波技术㺕展的前眳工作。研究內容包括了毫米波产 生、放大、停輸，精密的毫米波测量設备，毫米波尉 的超短脉冲技术，各种特殊波导和复杂波导元件的設 計和制作3 因此，对 TE 01 波型的波导傅輸的深入研 究和掌握, 将会使無电技术水平得到进一步的提高, 同时它将导致整个微波技术的重大革新。

远在1936年就會有人进行了沿金屬波导傳輸电磁 波的研究, 作了波长 13-23 厘米的微波在长度 382 米, 內直徑 15.24 厘米的波导內们傳送試驗, 但因当时所 用 $\mathrm{TE}_{\mu}$ 波型的傳輸耗挰太大，試驗結果未能指出用 波导将微波訊号作远距傳輸的可能性 [3]。

第二次世界大战期間由于無馢电定位技术的迅速

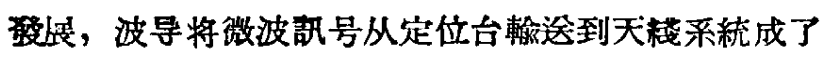
很重要的傳輸方法。战后这些年間微波技术不溯地在 向更短的波臤展，厘米及毫米波叚研究工作中所取 得的成就指出了使用波导作远距离傳輸溦波訊号的光 明前途。这些研究結果揭路了 $\mathrm{TE}_{01}$ 波型的晏米波在

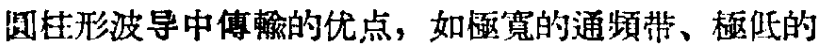

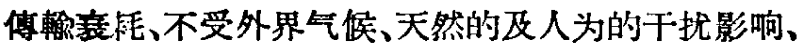
嗓声电平低等, 使科学家們預期到在毫米波波殿采用 波导管作远距离傳刺的現实性。这一問題的解决, 将 使由 35000 兆赫到 75000 兆赫的 40000 兆赫工作頻尉 內可以建立許多个通频带为几百兆赫的通訊䪙路[4] [5]。

目前無論在苏联或者在美国, 都正在大力地进行 着这方面的研究工作，捷克亦将于明年开始这方面的 研究。美国只尔实驗室已經于前两年有了 4 英里长的
波导傳軨綕，法这項研究工作（包括脉冲电碼調制 系統）的科学力量已超过 300 人，其中包括了多位推 界闑名的微波技术专家。

苏联科学院無綫电电子学研究所的波导傅輸实梌 窒在实驗室主任 Ю. И. 卡茲約切夫的須导下，和一采 列軍事及工業部門研究所配合着正在大力展开这少的 的研究工作 $[2]$ 。

在 1953 年以前苏联已經开始了部份的研究工你。 以后几年間进行了 $\mathrm{TE}_{01}$ 波在圆波导中傅輸理論和实: 驗两方面的研究, 导纫了新型自滤波导的理論, 井进 行了自㴽波导傳輸的实驗。在同一个时期中制作了部 多特殊的而又是最常用的波导綫路元件，等握了波导 桡路的量测方法和技术，㓣立了必需的和特殊的骨测 仪器, 得到了 $\mathrm{TE}_{01}$ 波在全金屬及周期性結构波导中 的全耗損的測量結果。研究結果會在苏联进行了深刻 的討論，以后又进行了許多方面的研究工作。在波导 傳輸系統方面，曾进行了选擇合适的工作波长，波导话 徑和中継放大站的距离的研究和有关其他基本要求的 研究。目前正在从事于各种調制方法和波导远距离傅

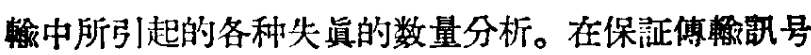
的可靠性和眞实性方面，通信理論早已指出脉冲电䂠 調制为最好的調制方法，苏联科学家的研究結果証明 傳选品質优良的彩色电視需要 7 个电碼系統, 这种通 訊系統需用特殊的宫速电子束开关管。和同軸通訊耤 及微波接力通訊綫不同，由于通頻带非常宽， $\mathrm{TE}_{01}$ 波 型的毫米波波导傳輸系統可以非常有效的采用胨沖电 碼調制方法，这就有可能使在远距离（到 10000 公里 甚至还要远些）傳輸訊号中畸变不积照起来。例如在 海参威到莫斯科电視中心發䢒的高質量的电視节日， 采用現在所有的通訊系統都不可能将电悓节目傅这到 这样远的距离而沒有干扰和畸变的积累, 只有用波马 通訊綫才可以使这种远距傅軨成为可能。

这种系統的本質在于使任何傳遞訊号叮以用脉济 电碼来代表，苏联已經有了由 5 个脉冲电硅組成的齐 統，可以得到 120 个不同的組合，作为傳垄非常是杂 訊号之用。利用脉冲电碼調制的毫米波波导通訊緍路 的原理是这样的：存波导傳期綫的始端有毫米波及其: 他無綫电的設备激受起所需要的脉冲。經过每50-1(1) 公里，这些毫米波段的脉冲訊号用相当的中繼站設备 加以放大。在长为 10000 公里的波导通訊䍃上每:个中 栈站有被控制的他激产生器, 产生器工作的开始偖赖

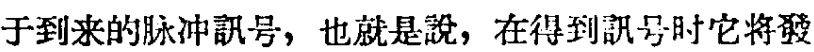
出从远方所送来的同样的脉冲，这样便可以得到完氺 恢复过来的浔有干扰及畸变积累的原始訊号。

在波导綫的中繼站必須具有毫米波放大設备，因 此，毫米波波段的行波放大管的制造是一項紧急的研 
究任务。为了这个目的, 苏联正在大力地进行这方面 的研究工作。

苏联科学家对 $\mathrm{TE}_{01}$ 波在非理想波导中傅軨的理 論和实騟两方面都做了不少的工作。首先，由于波导 傳輸是工作在衰耗特低的园电場 $\mathrm{TE}_{01}$ 高阶波型上 $\left(\mathrm{TE}_{\mathrm{u}} 、 \mathrm{TM}_{01}\right.$ 和 $\mathrm{TE} \mathrm{E}_{21}$ 型的截止波长都比 $\mathrm{T} \mathrm{E}_{01}$ 型的 更长, $\mathrm{TM}_{11}$ 型的栈止波长和 $\mathrm{TE}_{01}$ 型的相同。同时, 当 截面直徑比波长大很多时, 波导还能够傅輸比 $\mathrm{TE}_{01}$ 型 更高阶的許多波型)，因此如何滤去低阶波及其他高阶 波是一个很重要的問題。这个研究題目是与波导的不 均匀性和不規則性 (例如: 連接处、驾曲、歪曲部、孔 洞等等) 相关連的。波导的不規则部份会使某些类型 的商阶波更容易出現，而这些波的出現必然会使波导 的塞耗增加和使訊号的自实性受到影响，因此必須 没法加以防止。这項工作在不同方向进行着。例如， 研究內部表面是螺唗形的波导。这种結构的波导管的 特点是沿着它的表面組成周期性重复出現的裂縫, 这 种結构有效地阻碍許多奇生波的比現，因为这些类型 的波在波导的表面上有縱向的电流分量。这种周期性 結构的想法也曾用另一种环状結构的波导管的实驗絬 果来作比較。这种波导管是由銅环所組成, 在环之間 有間隚。

另一种新型波导也已經設計出来。在它的內部表 面上盖上一首牛导体带子, 带子的参数是这样选擇 的, 使在它里面除 $\mathrm{TE}_{01}$ 型的波以外，所有其他类型 的波都很快被辜减。研究結果指出，这种結构的波导 是很有成效的。用这种方法来防止波的变換, 首先是 由苏联科学院無电电子学研究所提出来的, 在这方 面还末看到英美方面有类似的研究工作报导。在苏 联, 許多秒特殊波导的样品已制造出来, 其实驗結果 与理論計算相符。

在世界上的無綫电技术的实踐中还沒有 $\mathrm{TE}_{01}$ 型 波的訊号产生器, 㚘且这种产生器可以直接接到园截 面的波导管上。这就必須将矩形波导中所产生的主波 轉变成在园形波导中的 $\mathrm{TE}_{01}$ 波型。苏联已經設計出 两种类型的波型轉換器。一种类型实际上是一段被面 由矩形逐漸改变为园形的长波导, 而另一种是由一段 矩形波导和一段园波导合抨而成的特殊方向偶合器。

現在在苏联科学院的波导傳輸实驗室中已經建立 了实驗性的波导綫路, 在这个綫路上进行了很多关于 在园波导中波的赛減問題的研究, 在与变形波导相联 系的各种現象的研究上也进行了很多的工作。在其中 还試驗了各种結构的特殊波导管, 探討了波导管的工 艺制造法和研究了很多还不够清楚的理論問題[2]。其
次还㓣立了測量在园波导中电磁波宰减的特殊力法， 制作了包括測量小段远沿导耗椇和各和金盗材料婊面 导电系的特种測量設备。利用这些特殊設备可以測量 波导表面光滑度对傳輸暴减的影响。前几隹苏联科学 家已开始应用 3 厘米超短脉冲方法来进行研究园波导 的不均匀性，找出波导中的不連續处，决定反射波的 功䇣，扞研究因波导的不均匀性所产生的各种类型的 寄生波。

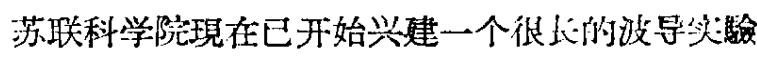
場。因此, 在短期內便可以从事許多公里上波导通訊 絓的研究。在这条比較长的实驗性波导通訊螕路上， 苏联科学家奇托了很大的希壁，这些研究結果将为进 一步开始建立真正远距离波导傳輸創浩㷙題。

目前实現远距离的波导傳輸, 保伱在一些实际困 难。首先，毫米波段的行波放大管有待进一步就展。 其次，特殊的脉冲电碼調制設备也需要制作消来。因 此，毫米波段波导远距离通訊的实現是和克服 $\mathrm{E}$ 大的 [难分不开的; 所有各方面涉及的理論与实际阔題都 是非常广泛的，需要有数学家、化学家、机械工程师 和無綫电电子学方面的工作人員紧沙的合作, 共同努 力使它早日实現。

最后，必須强調指出，不仅苏联許多的科学研究 机构在从事这項巨大而复杂的工作，其他一系列的工 業先进国家的工程和科学力量也忙于这項研究工作。 毫無疑問，我国也必須十分重視这一科学研究工作的 开展，因为毫米波段波导远距离傳輸問題的解决，必 然会为各种微波技术的發展开拓一个新的前进的基

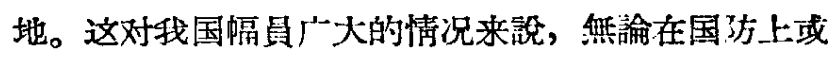
經济上都有巨大的意义。在苏联我們看到了苏联無綎 电电子学方面的科学家对我国科学事澲的热誠关怀, 他們很謙逊地表示，希望能和我們在这少面充分合 作。这对我們来馀，是一个努力学想苏联迅速赶上世 界科学水平的最好机会。我們应尽快地掌握苏联的現 有成就, 迎头赶上而不必从头摸菜。因此, 我椚应該 組織各方面的力量, 共同为迅速推动毫米波技术在我 国的建立和發展而奋斗。

[1] A. H. 湿斯米埸墸夫: “苏联科学院上作中的主要方 向”，顔交見科学通报，1957 年第 9 期。

[2] С. Ефимов: Наука и Жизнь, И-12, 1956.

[3] G. C. Southworth: B.S. T. J. XV, 284-309, April 1936.

[4] S. E. Miller: B. S. T. J. XXXII, 1209-1265, Nov. 1954.

[5] A. P. King: B. S. T. J. XXXV, 1115, Sept. 1956. 